\title{
Considerations in Flap Selection for Soft Tissue Defects of the Hand
}

\author{
Soumen Das De, MBBS (Hons), FRCSEd (Ortho), MPH*, \\ Sandeep Jacob Sebastin, MBBS, MRCS (UK), FAMS (Hand Surgery)
}

\section{KEYWORDS}

- Hand defects $\bullet$ Soft tissue reconstruction $\bullet$ Decision making • Flaps

\section{KEY POINTS}

- Soft tissue defects of the hand often involve composite tissue loss.

- Important decision-making parameters include location and size of the defect, associated digital soft tissue loss, and the technical complexity of the planned procedure.

- Aesthetic considerations are important in the choice of flap.

\section{INTRODUCTION}

Soft tissue defects of the hand are commonly encountered in the setting of trauma, infection, or burns and after resection of tumors. Small to moderate-sized defects are amenable to repair or reconstruction using linear closure, skin grafts, and/or local flaps. The usefulness of these procedures is limited, however, in larger defects or if there is a wide zone of injury and the adjacent tissue is of questionable viability. Free tissue transfers have obviated these issues of size and tissue availability but come at the cost of specialized expertise, resources, and risks. Furthermore, the aim of surgical reconstruction has extended from mere coverage of defects to optimizing both functional and aesthetic outcomes. ${ }^{1}$ The aim of this article is to discuss the considerations in soft tissue reconstruction of the hand and provide an approach that helps with decision making.

\section{CONSIDERATIONS IN RECONSTRUCTION OF THE HAND \\ Anatomic and Functional Considerations}

The hand spans the region between the distal wrist crease and the metacarpophalangeal joints
(MPJs). It has dorsal and palmar surfaces that are distinctly different. The dorsal skin is thin, pliable, and designed for mobility. This hairbearing skin has a certain amount of redundancy, especially over the wrist and MPJs. This allows it to accommodate wrist and finger flexion. The subcutaneous layer is thin and there is an underlying microvacuolar system that permits smooth gliding over the tendons and joints. ${ }^{2}$ There are welldefined points at which perforators emerge to nourish the overlying skin, and these form the basis of local perforator flaps. The palmar surface is designed for stability and load bearing. The specialized glabrous skin has a thick stratum corneum and numerous interdigitating dermal folds to withstand shear stresses. The epidermal ridges and the high density of sweat glands increase the surface area and frictional forces for grip. The palmar skin is firmly tethered to the underlying fibrous framework-particularly at the creasesand this confers stability during grasp and pinch. These numerous septations, however, also make palmar skin relatively immobile and limit the availability of local flap options from the palm.

The upper limb has a tapering design, becoming progressively narrower from proximal to distal. ${ }^{1,3}$

Disclosures: No conflicts of interest.

Department of Hand \& Reconstructive Microsurgery, National University Health System, 1E Kent Ridge Road, Singapore 119 228, Singapore

* Corresponding author.

E-mail address: das_de_soumen@nuhs.edu.sg 
Thus, there is greater availability of soft tissue proximally. There also is more laxity of skin along the longitudinal axis compared with the transverse axis of the limb. These anatomic concepts form the basis of regional flaps from the forearm to resurface hand defects. These flaps may contain an axial pedicle (eg, radial artery or posterior interosseous artery [PIA]) or perforators from the axial vessels. The maximum length and width of perforator flaps are smaller than axial pedicle flaps.

\section{Aesthetic Considerations}

The aesthetic principles of hand reconstruction deserve special mention. Summers and Siegle described a facial cosmetic unit as "a major structural unit of the face that shares similar skin characteristics of color, texture, thickness, elasticity, pore density and size, hairiness, and sebaceousness." ${ }^{4}$ Rehim and colleagues ${ }^{5}$ expanded on the cosmetic units of the hand that were originally described by Tubiana. The palmar unit is divided into the thenar, opposition, central triangular, hypothenar, and metacarpal subunits. The dorsal surface of the hand is a single unit. The skin over each phalanx of the fingers and thumb is considered a single subunit. The nail complex and pulp are special subunits because of their unique functional and aesthetic properties (Fig. 1).

\section{PREREQUISITES FOR SOFT TISSUE COVERAGE IN THE HAND}

Definitive reconstructive procedures are undertaken only when the wound is free of infection, all nonviable tissue has been removed, and there is a stable skeletal framework. Other considerations in planning soft tissue reconstruction for hand defects include the following.

\section{Avoid Excessive Granulation and Scar Formation}

The use of vacuum-assisted closure devices promotes granulation, even over poorly vascularized tissue, such as tendon and bone. In the hand, excessive granulation obliterates the gliding planes that exist between the joints, tendons, and skin and leads to adhesions and stiffness. ${ }^{6}$ Skin grafts that are applied to such surfaces may take, but the period of immobilization required for skin grafts take along with graft contracture lead to more adhesions and further limitation of motion. For this reason, the authors do not recommend prolonged application of negative-pressure dressings unless the defects are small and/or other patient factors preclude more complex reconstructive procedures. A cutaneous flap is preferred because it allows earlier mobilization and restoration of the gliding plane between tendon and skin.

\section{Use a Thin Flap}

The primary goal of soft tissue reconstruction in the hand is to ensure that the fingers regain normal or near-normal motion. This requires thin and pliable skin that allows digital flexion and gliding of the underlying tendons. A bulky flap may impair finger flexion if used for reconstruction of the palm. Although an adipofascial flap with a skin graft provides a thin flap, the authors have had poor outcomes with adipofascial flap reconstructions in the hand. The skin graft contracts significantly, limiting motion, obviating any perceived advantages of the thin flap. In addition, it is easier to elevate a cutaneous flap compared with the adipofascial flap for any secondary surgery.

\section{Determine if There Are Digital Soft Tissue Defects that Need Coverage}

The presence of finger and/or thumb defects that require concomitant soft tissue coverage significantly affects the reconstructive strategy. Propeller flaps based on perforators of the radial and ulnar arteries are not long enough to safely resurface the web space and skin over the proximal phalanx. The pivot points of these flaps are approximately $2 \mathrm{~cm}$ to $5 \mathrm{~cm}$ proximal to the wrist crease, and the maximum safe dimensions of these flaps are $12 \mathrm{~cm}$ by $4 \mathrm{~cm}^{3}$ Regional flaps from the forearm based on an axial pedicle (eg, reverse radial forearm flap [RFF] or posterior interosseous artery [PIA] flap) require an extended pedicle design to safely reach the web space and proximal phalanx. Larger hand defects extending beyond the proximal interphalangeal joint require a distant (eg, groin) or free flap and creation of a syndactyly with subsequent division, if multiple digits require resurfacing.

\section{Maintain the Aesthetics of the Hand}

Although aesthetics traditionally were not the primary goal of reconstruction, they do affect a patient's acceptance of a reconstructive procedure. An unsightly outcome may result in a hand that is hidden in a pocket and an anxious and depressed patient. Factors that influence the aesthetic outcome of a reconstruction are color and texture match, donor-recipient tissue interface, hairiness, scar location and propensity for contractures, nail deformities, presence of amputations, and donor site appearance. ${ }^{5}$ Every effort should be made to incorporate these factors when deciding on the reconstructive strategy. Skin incisions 

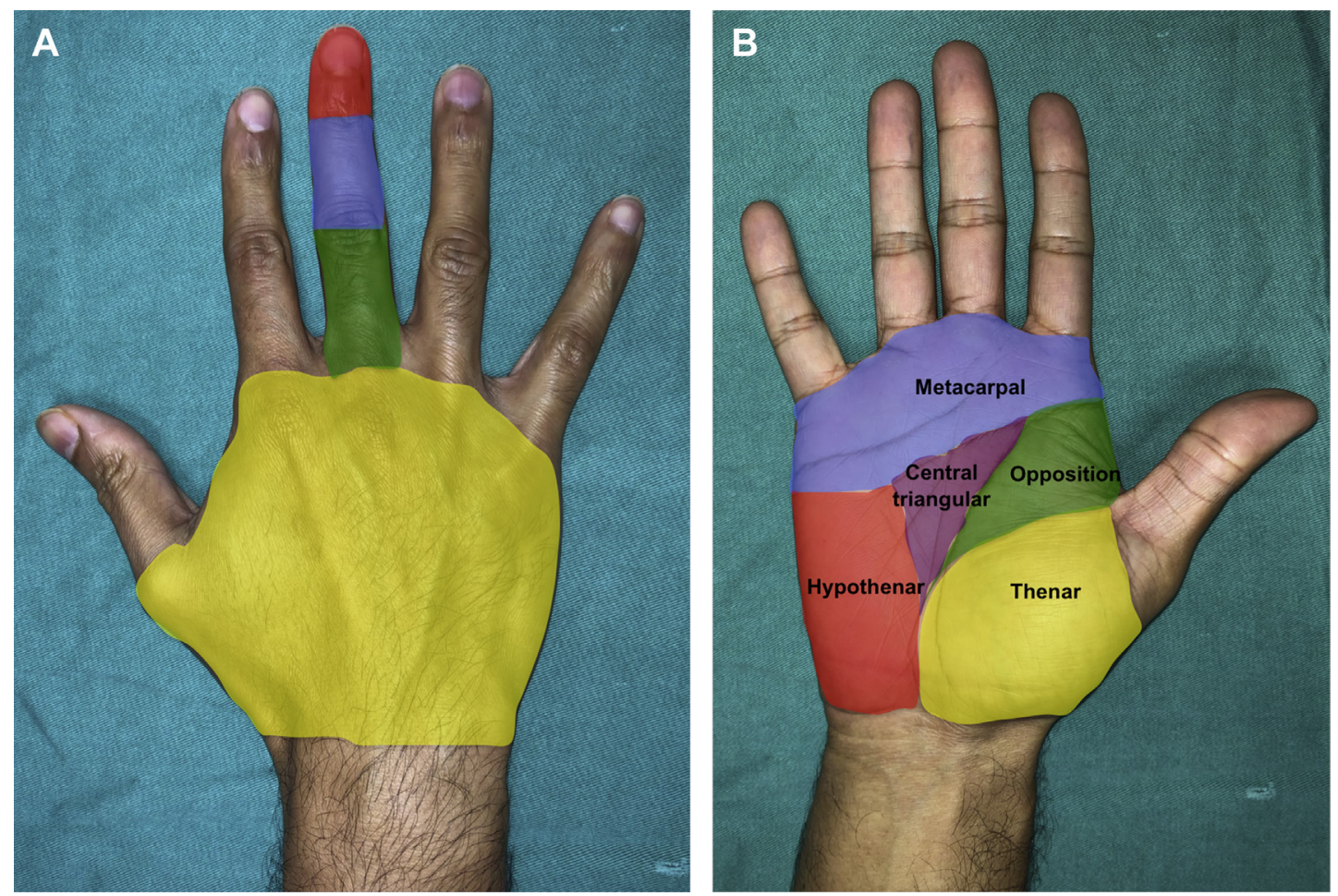

Fig. 1. The functional aesthetic units of the hand. $(A)$ The dorsum of the hand is a single unit, comprising thin, pliable, hair-bearing skin. The skin over each of the phalanges of the fingers and thumb is a functional subunit. The nail complex is a specialized subunit because of its unique functional and aesthetic properties. $(B)$ The palmar unit of the hand is made up of 5 functional subunits - thenar, opposition, central triangular, hypothenar, and metacarpal. As in the dorsum, the skin over each phalanx is a separate subunit and the pulp has unique functional properties. The boundaries of these subunits are demarcated by skin creases and the undulating surfaces reflect light to differing degrees, accounting for the typical light-dark contrasts of the normal hand. Incisions planned in the boundaries of these functional subunits tend to be concealed and are aesthetically pleasing. Scars, skin grafts, or flaps that break up this normal color contrast confer an abnormal 3-D appearance, and the result is a cosmetically unattractive hand.

should be planned in relatively concealed regions (eg, medial forearm) or along boundaries of functional units (eg, the midaxial surface of the hand or digit). Skin grafts used by themselves provide poor volume replacement and are reserved for small defects with a healthy subcutaneous bed. The authors prefer to use like-for-like skin grafts. Dorsal hand defects are best resurfaced with grafts taken from the medial or dorsal forearm (Fig. 2) and there are several donor sites for glabrous skin to cover palmar defects. ${ }^{7,8}$ Regional flaps from the forearm leave conspicuous donor defects and result in significant color mismatch in dark-skinned individuals. These flaps should be reserved for dorsal hand defects because of the good color and texture match. Free fasciocutaneous flaps (eg, anterolateral thigh [ALT] and lateral arm) provide a reasonable color match with a relatively concealed donor site but tend to be bulky. Suprafascial flap elevation or staged debulking/liposuction may be necessary. Free muscle flaps (eg, gracilis) provide good volume replacement in the setting of extensive soft tissue loss. Perforator-based propeller flaps probably offer the best compromise; they provide like-forlike replacement, are relatively easy to perform, and do not require sacrifice of a dominant vessel, and the donor site may be linearly closed in many instances.

\section{CLASSIFICATION OF SOFT TISSUE DEFECTS OF THE HAND}

The authors categorize hand defects based on the following parameters:

- Surface

- Size

- Location

The defect may be located on the palmar, dorsal, or lateral (midaxial) surface of the hand or a combination of more than 1 surface. Because of 


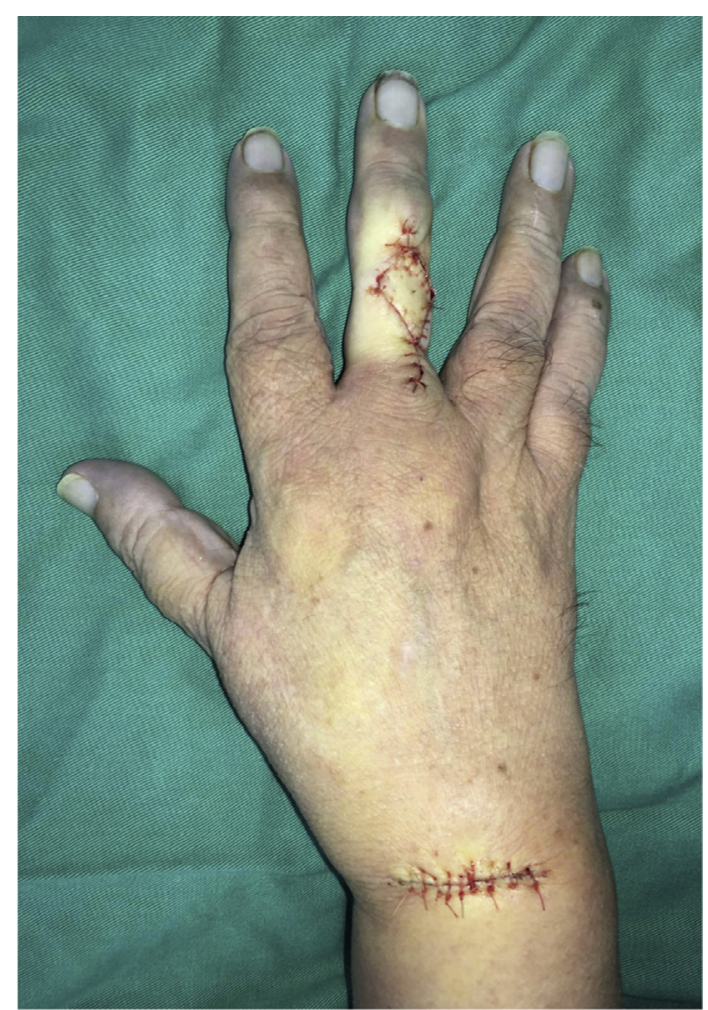

Fig. 2. Resurfacing small defects using like-for-like skin grafts. An elderly patient with advanced dementia sustained a dorsal finger infection after a cat bite. The resultant defect after débridement was resurfaced with a full-thickness skin graft obtained from the dorsum of the wrist. This site was chosen because both the defect and the donor site could be safely protected in a cast. The dorsal skin provides an excellent color and texture match, and the transverse skincrease incision will heal with a concealed scar.

the unique properties of glabrous skin, the authors have simplified defect surfaces into dorsal and palmar defects. The relative size of the defect is more important than an absolute measurement. One surface of a single metacarpal has been described as a unit. ${ }^{1}$ Small defects comprise a single surface of a metacarpal (eg, dorsal or palmar). Medium-sized defects involve 2 adjacent surfaces of a metacarpal (eg, dorsal and lateral) or contiguous surface of 2 adjacent metacarpals (eg, dorsal surfaces of index and middle metacarpals). Anything larger is considered a large defect and includes involvement of noncontiguous surfaces. Finally, the authors divide the hand into radial, central, and ulnar thirds based on location to aid in the choice of appropriate flaps. The radial third comprises the first metacarpal (thumb) and includes the thenar region and the first web space; the central third spans the second and third metacarpals (index and middle fingers); and the ulnar third includes the fourth and fifth metacarpals (ring and small fingers). Additional factors in decision making are summarized in Box 1.

\section{FORMULATING RECONSTRUCTIVE STRATEGY BASED ON CLASSIFICATION Surface (Dorsal and Palmar)}

The dorsum of the hand excluding the digits measures approximately $10 \mathrm{~cm}$ wide by $12 \mathrm{~cm}$ long. Dorsal soft tissue defects commonly are associated with injury to the tendons, bones, and joints and frequently require a flap. The laxity of dorsal skin makes it suitable for local flaps, based on a random pattern of vascularization, an axial pedicle, or a perforator. It is uncommon to encounter injuries that result in loss of the entire palmar skin. The skin is thick and soft tissue defects usually have a healthy subcutaneous bed, which takes a split-thickness skin graft. Glabrous skin is also unique for the reasons discussed earlier and in limited supply, with the only other source the plantar surface of the foot. Skin over the thenar subunit is mobile, whereas the skin over the central triangular and metacarpal subunits has minimal laxity. Consequently, most of the local palmar flaps arise from the thenar and radial midpalmar regions.

Box 1

Considerations in soft tissue reconstruction of the hand

Defect characteristics

- Size

- Depth

- Location

- Finger/thumb involvement

- Additional tissues involved, for example, bone, tendon, and nerve

Technical considerations

- Level of difficulty

- Available resources

Patient factors

- Hand dominance

- Occupation and functional demands

- Preexisting illnesses, for example, diabetes, peripheral vascular disease, and renal impairment

- Compliance to postoperative rehabilitation plan

- Cosmetic concerns, preferences, and expectations 


\section{Size (Small, Medium, and Large)}

The reconstructive options available for the hand include healing by secondary intention, skin grafts, local random pattern flaps, pedicled perforatorbased flaps, pedicled axial pattern flaps, pedicled distant flaps, and free flaps. Small defects may be amenable to healing by secondary intention or skin grafting (palmar defects). The other options include random pattern local flaps like rotation or transposition (dorsal defects). In general, perforator-based flaps are suitable for small defects and some medium-sized defects, axial pattern flaps are suitable for medium-sized effects and some large defects, and distant pedicled or free flaps are suitable for large defects.

\section{Location (Radial, Central, and Ulnar)}

Tables 1 and 2 summarize the options for reconstructions of soft tissue defects of the hand based on the surface, size, and location of the defect. Reconstructive options are discussed.

\section{PEDICLED PERFORATOR-BASED LOCAL FLAPS}

These options are only viable if the zone of injury is limited and the blood supply to the skin adjacent to the defect is maintained. Ideally, the reconstructive surgeon should perform the initial débridement(s) for several reasons. First, it is crucial that any skin

\begin{tabular}{|c|c|c|}
\hline \multicolumn{3}{|c|}{$\begin{array}{l}\text { Table } 1 \\
\text { Options for dorsal hand defects }\end{array}$} \\
\hline $\begin{array}{l}\text { Small Defects } \\
\text { (1 Unit) }\end{array}$ & $\begin{array}{l}\text { Medium } \\
\text { Defects } \\
\text { (2 Units) } \\
\end{array}$ & $\begin{array}{l}\text { Large Defects } \\
\text { (More Than } \\
2 \text { Units) } \\
\end{array}$ \\
\hline $\begin{array}{l}\text { Skin grafts } \\
\text { - Medial } \\
\text { forearm } \\
\text { - Groin } \\
\text { Local flaps } \\
\text { - Random } \\
\text { pattern flap } \\
\text { Radial defects } \\
\text { - FDMA flap } \\
\text { - RAP flap } \\
\text { Central defects } \\
\text { - Dorsal } \\
\text { metacarpal } \\
\text { artery } \\
\text { perforator } \\
\text { flap } \\
\text { - PIA flap } \\
\text { Ulnar defects } \\
\text { - UAP flap }\end{array}$ & $\begin{array}{l}\text { Radial defects } \\
\text { - RAP flap } \\
\text { - Reverse RFF } \\
\text { - Extended RFF } \\
\text { Central defects } \\
\text { - PIA flap } \\
\text { - Extended } \\
\text { PIA flap } \\
\text { Ulnar defects } \\
\text { - UAP flap }\end{array}$ & $\begin{array}{l}\text { Distant } \\
\text { - Groin/ } \\
\text { abdominal } \\
\text { flap } \\
\text { Free } \\
\text { - ALT flap } \\
\text { - Medial } \\
\text { sural } \\
\text { artery } \\
\text { perforator } \\
\text { flap } \\
\text { - Dorsalis } \\
\text { pedis flap } \\
\text { - RFF } \\
\text { - Lateral } \\
\text { arm flap }\end{array}$ \\
\hline
\end{tabular}

Abbreviations: RAP, Radial artery perforator; UAP, Ulnar artery perforator.

\begin{tabular}{|c|c|c|}
\hline \multicolumn{3}{|c|}{$\begin{array}{l}\text { Table } 2 \\
\text { Options for volar hand defects }\end{array}$} \\
\hline $\begin{array}{l}\text { Small Defects } \\
\text { (1 Unit) }\end{array}$ & $\begin{array}{l}\text { Medium } \\
\text { Defects } \\
\text { (2 Units) }\end{array}$ & $\begin{array}{l}\text { Large Defects } \\
\text { (More Than } \\
2 \text { Units) }\end{array}$ \\
\hline $\begin{array}{l}\text { Secondary } \\
\text { intention } \\
\text { Skin grafts } \\
\text { - Palm } \\
\text { (hypothenar, } \\
\text { skin creases) } \\
\text { Radial and } \\
\text { central } \\
\text { defects } \\
\text { - Reverse } \\
\text { thenar } \\
\text { perforator } \\
\text { flap } \\
\text { - Radial } \\
\text { midpalmar } \\
\text { island flap } \\
\text { - Volar glabrous } \\
\text { palm flap } \\
\text { Ulnar defects } \\
\text { - Ulnar } \\
\text { palmar } \\
\text { perforator } \\
\text { flap }\end{array}$ & $\begin{array}{l}\text { Preferred } \\
\text { options } \\
\text { - Medialis } \\
\text { pedis free } \\
\text { flap } \\
\text { - MPA free } \\
\text { flap } \\
\text { Alternatives } \\
\text { - RAP flap } \\
\text { (radial } \\
\text { defects) } \\
\text { - UAP flap } \\
\text { (ulnar } \\
\text { defects) }\end{array}$ & $\begin{array}{l}\text { Distant } \\
\text { - Groin/ } \\
\text { abdominal } \\
\text { flap } \\
\text { Free } \\
\text { - ALT flap } \\
\text { - Medial } \\
\text { sural artery } \\
\text { perforator } \\
\text { flap } \\
\text { - Dorsalis } \\
\text { pedis } \\
\text { flap } \\
\text { - RFF } \\
\text { - Lateral } \\
\text { arm } \\
\text { flap }\end{array}$ \\
\hline
\end{tabular}

Abbreviations: RAP, Radial artery perforator; UAP, Ulnar artery perforator.

extensions to explore adjacent neurovascular structures, tendon or bone do not damage the adjacent perforators. Second, the adjacent skin must be inspected carefully for degloving because such injuries are likely to compromise the perforators. Third, digital blocks should be avoided because they may damage the perforators, in particular the veins. Finally, the reconstructive surgeon may look for sizable perforators in the vicinity during the initial wound débridement, although the authors do not recommend any further vessel dissection because of the risk of vasospasm. Some of the common perforator-based pedicled laps suitable for hand reconstruction include

1. First dorsal metacarpal artery (FDMA) flap: this is a good choice for small defects of the thumb and first web space. ${ }^{9}$ The FDMA arises from the deep branch of the radial artery and it reliably perfuses the dorsal skin up to the middle of the proximal phalanx of the index finger. The flap may be raised as an island or with a tail of skin from the dorsum of the first web space. It is important that the FDMA is retained in a broad strip of fascia and not skeletonized during flap elevation, and inclusion of a cutaneous vein minimizes the risk of flap congestion. 
2. Dorsal metacarpal artery perforator flap: the dorsal metacarpal artery perforator (Quaba) flap offers a straightforward option for small defects over metacarpals, the web spaces, and the proximal phalanges. ${ }^{10}$ The cutaneous perforators of the dorsal metacarpal artery arise at the level of the metacarpal neck in the second to fourth intermetacarpal spaces, just distal to the juncturae tendinum. The skin over the dorsum of the hand is thin and pliable and provides an excellent match for resurfacing dorsal hand and finger defects. The flap can reliably resurface defects up to the middle of the proximal phalanx and the donor defect can be closed linearly in most cases. A curved elliptical design can be used to obtain more distal reach when the flap is rotated and straightened. Finally, the authors avoid tunneling the flap under an intact skin bridge.

3. Radial artery perforator (RAP) flap: Timmons ${ }^{11}$ described the distribution of cutaneous perforators arising from the radial artery in 1986. A majority of these congregate around the radial styloid. ${ }^{12,13}$ Koshima and colleagues ${ }^{14}$ demonstrated the use of an adipofascial flap based on these perforators for reconstruction of dorsal hand defects. The optimal dimensions of the RAP flap are $12 \mathrm{~cm}$ by $4 \mathrm{~cm}$ although flaps up to $18 \mathrm{~cm}$ in length have been described. ${ }^{3,12}$
The authors prefer to use the RAP to resurface small to medium-sized defects on the radial surface of the hand, particularly on the dorsum because of the good color and texture match (Fig. 3). The lateral antebrachial cutaneous nerve can be included to provide a sensate flap. Chang and colleagues ${ }^{12}$ advocated ligation of the cephalic vein at the base of the flap because a patent vein caused significant flap congestion and compromised viability. The RAP flap does not reliably reach beyond the MPJ and alternative options should be selected for concomitant coverage of digital defects. ${ }^{15}$

4. Ulnar artery perforator (UAP) flap: Becker and Gilbert ${ }^{16}$ described the ulnar flap based on a dorsal branch of the ulnar artery, passing deep to the flexor carpi ulnaris (FCU) muscle. This flap is a good choice for small to medium-sized defects involving the ulnar side of the hand and wrist. The volar (radial) incision is made first and suprafascial dissection continued ulnarly until the FCU tendon is identified. The dissection is then continued subfascially while the FCU tendon is retracted radially. The ulnar artery is identified, and a suitable perforator is selected. Reliable perforators from the ulnar artery may be found 4 to $6 \mathrm{~cm}$ proximal to the pisiform. ${ }^{3,17}$ Mathy and colleagues ${ }^{18}$ studied the entire course of the ulnar
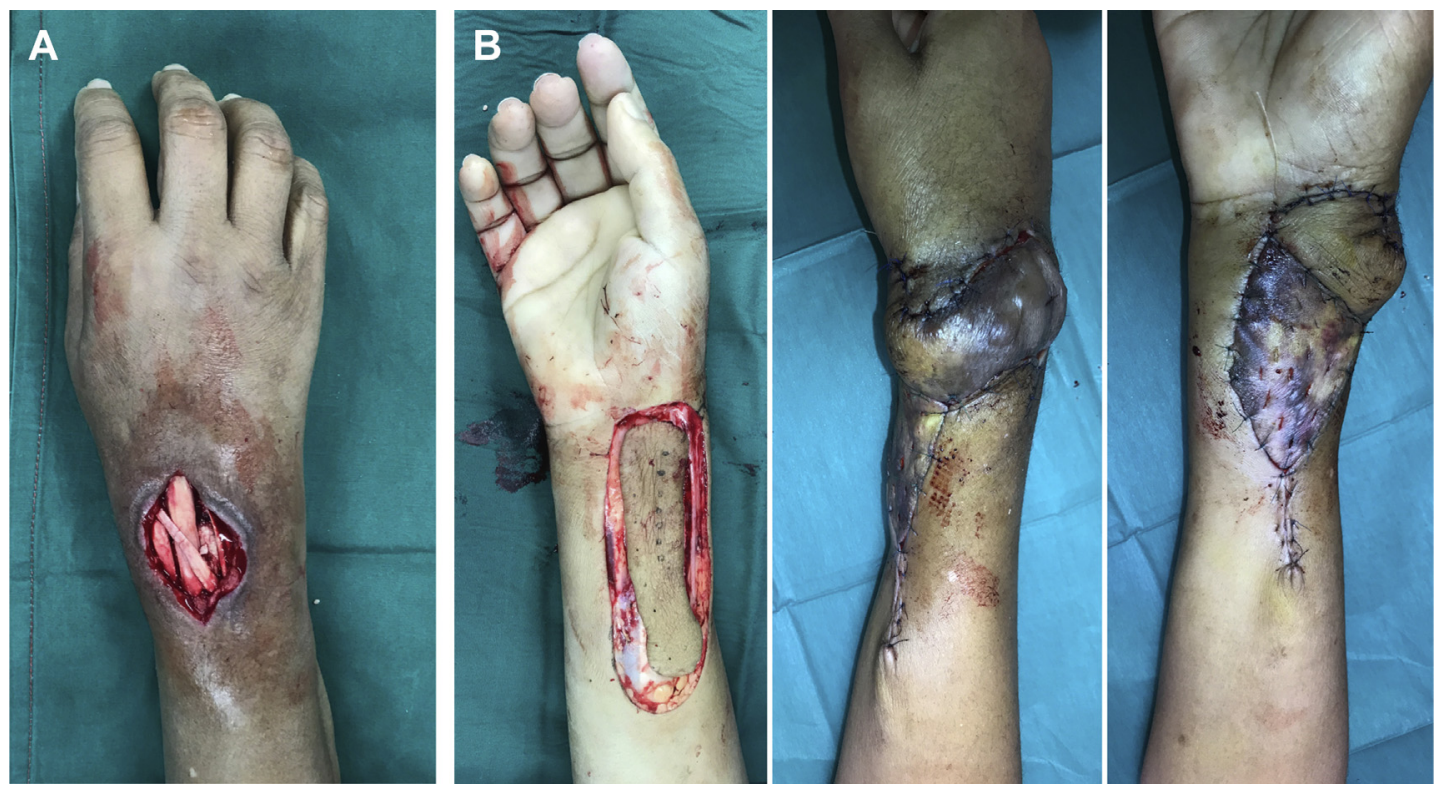

Fig. 3. RAP flap. $(A)$ This patient sustained a cannula-site infection. The resultant defect after débridement was over the dorsum of the wrist and proximal hand, with exposed wrist and finger extensor tendons. (B) An RAP flap was used to resurface the defect (left). The donor defect was covered with a hand-meshed split-thickness skin graft. There was superficial epidermolysis of the distal part of the flap (center). The RAP provides a good match for dorsal hand/wrist defects and preserves the radial artery. The donor site, however, is conspicuous (right). 
artery and reported that $94 \%$ of forearms had at least 1 sizable $(>0.5-\mathrm{mm})$ cutaneous perforator within $3 \mathrm{~cm}$ of the midpoint of a line connecting the medial epicondyle and pisiform. All forearms had at least 1 perforator within $6 \mathrm{~cm}$ of the midpoint. In their series, $6 \%$ of flaps had perforators originating from an anomalous superficial ulnar artery. Any of these perforators can therefore be incorporated in flaps to resurface more proximal forearm defects. The advantages of this flap over the RAP flap are the more concealed incision and relatively hairless skin in this part of the forearm. Skin grafts used to cover larger donor defects tend to heal better because the grafts are applied over muscle rather than tendons/paratenon in the case of a RAP flap (Fig. 4).

5. Glabrous skin perforators flaps: small radial and central defects can be resurfaced with perforator flaps arising from the thenar region. They have been variously named the radial midpalmar island flap, ${ }^{19}$ reverse thenar perforator flap,,$^{20,21}$ and the volar glabrous palmar flap. ${ }^{22}$ These flaps measure, on average, $5 \mathrm{~cm}$ by $2 \mathrm{~cm}$ and rely on the laxity of the thenar skin. There is a confluence of arteries at the thenar region, where the superficial palmar arch meets the superficial palmar branch of the radial artery, the radialis indices artery, and the princeps pollicis artery. ${ }^{19,20}$ Perforators arising from this confluence form the basis of propeller or reverse-flow flaps. Alternatively, a free flap may be harvested based on the superficial palmar branch of the radial artery itself. Small ulnar defects (eg, over the hypothenar border) usually do not result in exposure of critical structures and are amenable to skin grafting or healing by secondary intention. In selected cases, the ulnar palmar perforator flap can be used to resurface palmar defects measuring approximately $2 \mathrm{~cm}$ by $6 \mathrm{~cm} .^{23}$ The flap is based on a septocutaneous perforator from the ulnar digital artery to the small finger, emerging between the hypothenar muscles at the level of the metacarpal neck.

\section{PEDICLED AXIAL PATTERN FLAPS Radial Forearm Flap}

The RFF or the adipofascial RFF can be used for small to medium-sized defects over the radial and central compartments. ${ }^{6}$ Since its first description as a free flap in 1978, the RFF has remained one of the most versatile flaps in reconstructive surgery. ${ }^{24}$ The RFF used for resurfacing hand defects is essentially a reverse-flow flap and relies on a patent ulnar artery-radial artery communication in the hand. The RFF is relatively easy to raise and reliable and provides thin, pliable skin for soft tissue resurfacing. An extended pedicle may be obtained if the superficial branch of the radial artery is ligated and the pivot point is based on the deep branch of the radial artery, just before it dives volarly around the base of the thumb metacarpal. The extended RFF can be used to extend the reach of the flap to resurface defects over the web spaces and MPJ (Fig. 5). The main drawbacks of this flap
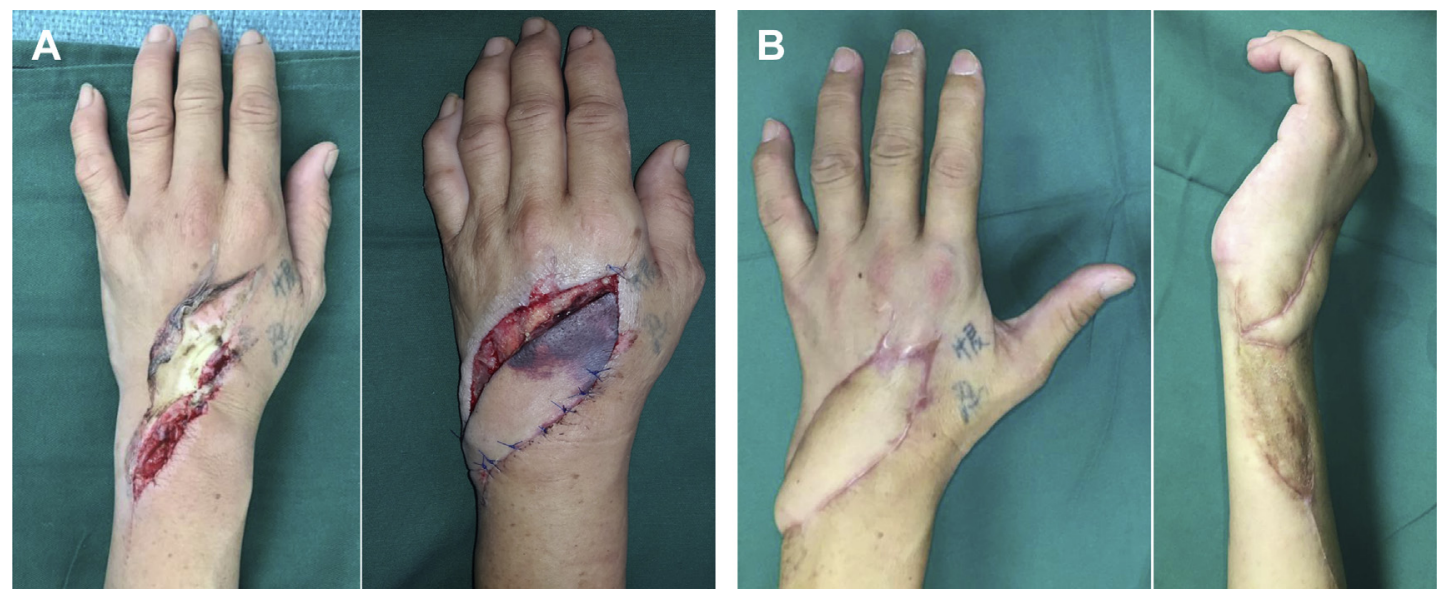

Fig. 4. UAP flap. $(A)$ This patient sustained a crush injury from factory machinery, and the result is an untidy dorsal wound with an area of full-thickness skin burn. The underlying extensor tendons were disrupted (left). All unhealthy skin was excised and the extensor tendons were repaired. A UAP flap was used to cover the resultant defect. The flap was partially inset at the initial stage; nevertheless, there is epidermolysis of the tip (right). $(B)$ The final outcome is aesthetically pleasing with good color and texture match (left). The skin grafted donor site is concealed and not easily visible (right). 

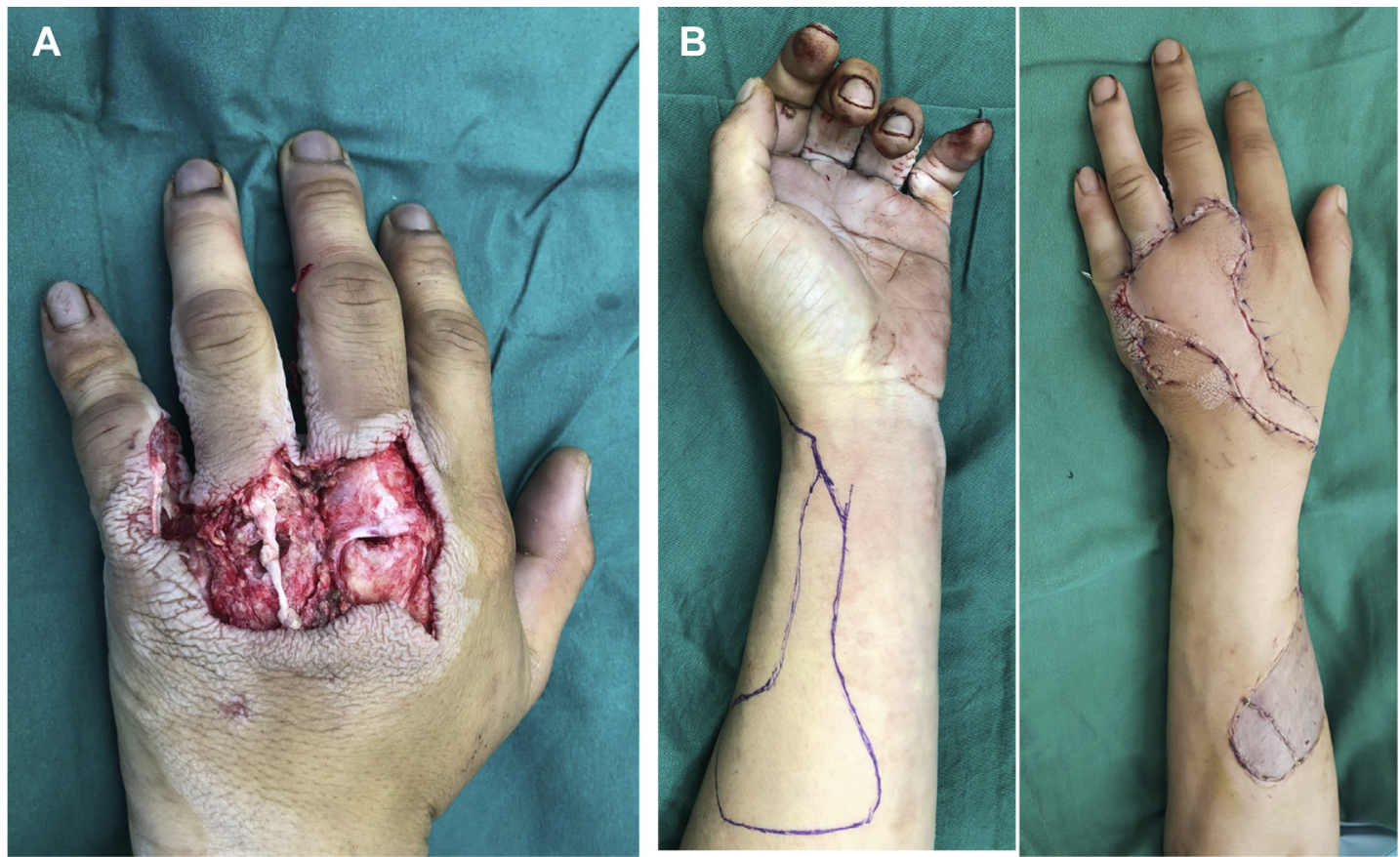

Fig. 5. Reverse RFF. (A) A motor vehicle accident resulted in a composite defect of the dorsum of the hand involving loss of extensor tendons, partial loss of MPJ surfaces, and a comminuted fracture of the small finger proximal phalanx. There was extensive particulate contamination and a radical débridement was performed. $(B)$ Soft tissue reconstruction was achieved using an extended RFF (left) and the donor site was covered using a split-thickness skin graft. Bone and tendon grafting were deferred to a later stage because of the extensive initial contamination. The flap provides good color and texture match, but the donor site is conspicuous. Hand-meshing the skin graft results in a more uniform and pleasing appearance (right).

are sacrifice of a major vessel to the hand, a poor color match-especially for the palmar surface of the hand, and a cosmetically unappealing donor site. The cosmetically unappealing donor site can be addressed with the use of a reversed adipofascial RFF and skin grafting, with primary closure of the donor site. ${ }^{25}$ This is not recommended, however, if delayed procedures are planned, for example, bone grafting and tendon reconstruction.

\section{Posterior Interosseous Artery Flap}

The PIA flap was described by Angrigiani and Zancolli and is a versatile flap that does not require sacrifice of a major artery. ${ }^{26,27}$ The reverse-flow PIA flap relies on a patent communication between the anterior interosseous artery (AIA) and PIA at the level of the carpus and is ideal for defects over the central and ulnar parts of the dorsum of the hand (Fig. 6). The pivot point of the flap is $2 \mathrm{~cm}$ proximal to the distal radioulnar joint, where the communicating branch from the AIA emerges through the interosseous membrane to meet the PIA. A line connecting the lateral epicondyle and the distal radioulnar joint denotes the axis of the flap. The authors recommend making the ulnar incision first and identifying the extensor carpi ulnaris (ECU) tendon. The extensor digiti minimi (EDM) tendon is identified next and gentle traction with a tendon hook can be used to confirm its action on the small finger. The communicating perforator between the AIA and PIA is identified in the interval between the EDM (fifth extensor compartment) and ECU (sixth extensor compartment). The authors make it a point to identify this perforator before proceeding with the rest of flap harvest because the carpal communication and/ or the distal PIA may be absent in approximately $5 \%$ of the population. ${ }^{27-29}$ A large cutaneous perforator from the PIA (the so-called median cutaneous branch) is found approximately midway along the axis, and this part is incorporated into the flap design. ${ }^{27}$ The proximal (safe) limit of the flap is at a point $6 \mathrm{~cm}$ distal to the lateral epicondyle and the PIA is ligated here, proximal to the emergence of the medial perforator. More proximal dissection requires separation of the motor branch of the PIA nerve to the 

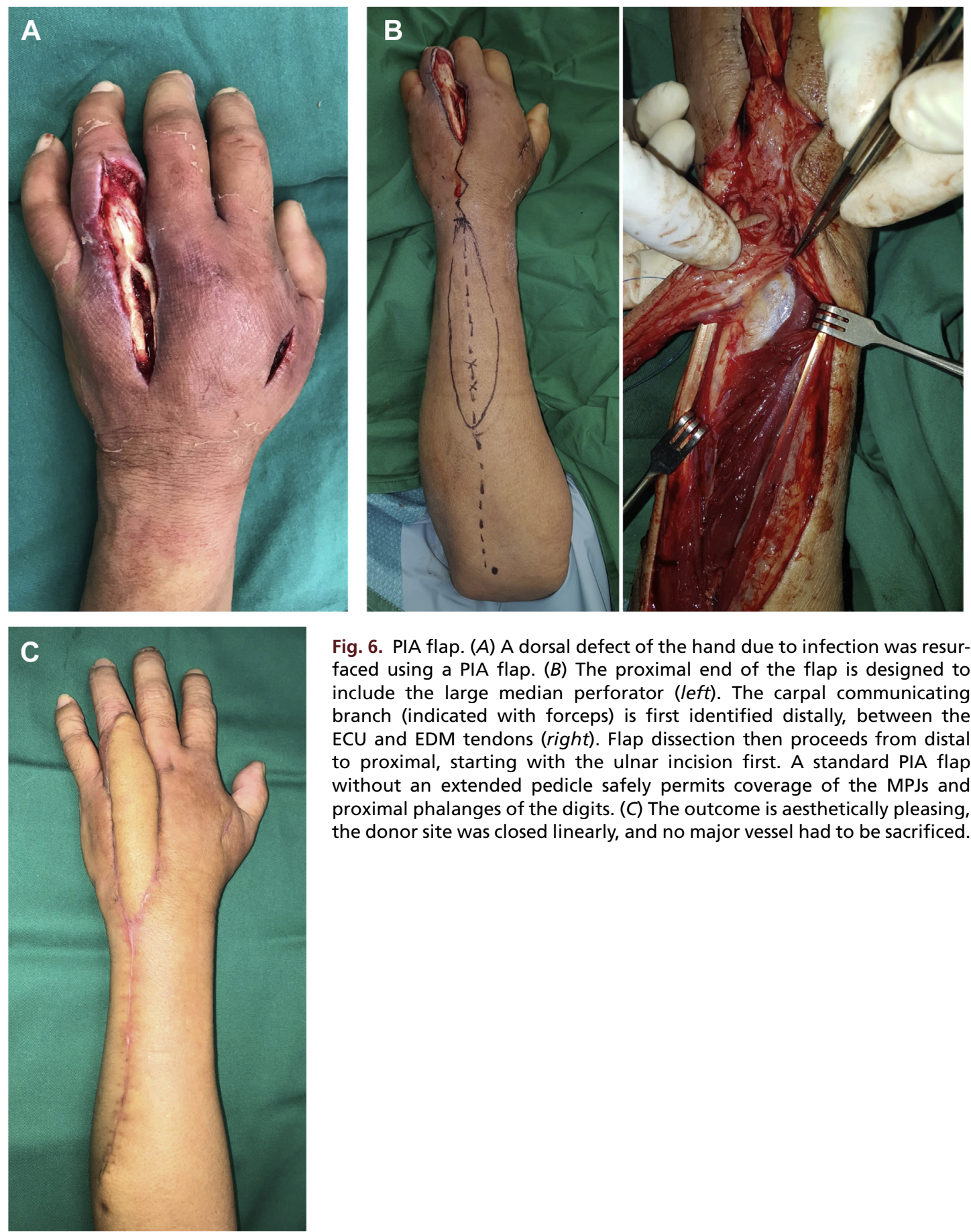

Fig. 6. PIA flap. (A) A dorsal defect of the hand due to infection was resurfaced using a PIA flap. $(B)$ The proximal end of the flap is designed to include the large median perforator (left). The carpal communicating branch (indicated with forceps) is first identified distally, between the ECU and EDM tendons (right). Flap dissection then proceeds from distal to proximal, starting with the ulnar incision first. A standard PIA flap without an extended pedicle safely permits coverage of the MPJs and proximal phalanges of the digits. (C) The outcome is aesthetically pleasing, the donor site was closed linearly, and no major vessel had to be sacrificed.

ECU from the flap pedicle and, in circumstances where the artery lies deep to the nerve branch, the latter has to be sacrificed. ${ }^{30}$ The donor defect can be closed linearly in flaps measuring $3 \mathrm{~cm}$ to $4 \mathrm{~cm}$ in width. Zaidenberg and colleagues $^{31}$ demonstrated an "extended PIA flap" based on the communication between the PIA and dorsal intercarpal arch. The more distal pivot point allows the flap to cover the web spaces and digits. 


\section{DISTANT PEDICLED FLAPS}

The lower abdomen has several arteries emanating from the external iliac and superficial femoral arteries that can reliably be used for soft tissue coverage of the hand. These are the superficial circumflex iliac artery (SCIA), superficial inferior epigastric artery (SIEA), superficial external pudendal artery, deep inferior epigastric artery, and the paraumbilical perforators. Pedicled groin and hypogastric flaps have become the workhorse for soft tissue reconstruction of the hand and have been extensively described in the literature. Complex defects can be reconstructed using a combination of flaps (Fig. 7). These flaps are easy to raise and do not require microsurgical expertise or sacrifice of a major artery. The obvious drawback is having the hand strapped to the trunk for 2 weeks to 3 weeks in a dependent position and delaying rehabilitation.
Al-Qattan and Al-Qattan ${ }^{32}$ recently reviewed the indications for these flaps in the microsurgical era and concluded that there remained specific situations where these flaps are strongly indicated. These include hand defects in small children, soft tissue coverage prior to toe transfers, high-voltage electrical burns with questionable patency of the major arteries, and multiple hand and digital defects.

There are specific design elements that can optimize patient comfort and clinical outcomes. The surgeon should bring the hand to the groin and work backwards. Chuang and colleagues ${ }^{33}$ described a simple method of defining the safe boundaries of the groin flap. Sabapathy and Bajantri ${ }^{34}$ highlighted some basic principles concerning flap design and inset: adequate débridement, keeping the base narrow and the pedicle long, thinning the distal end, and performing a robust inset. They did not advocate tubing the
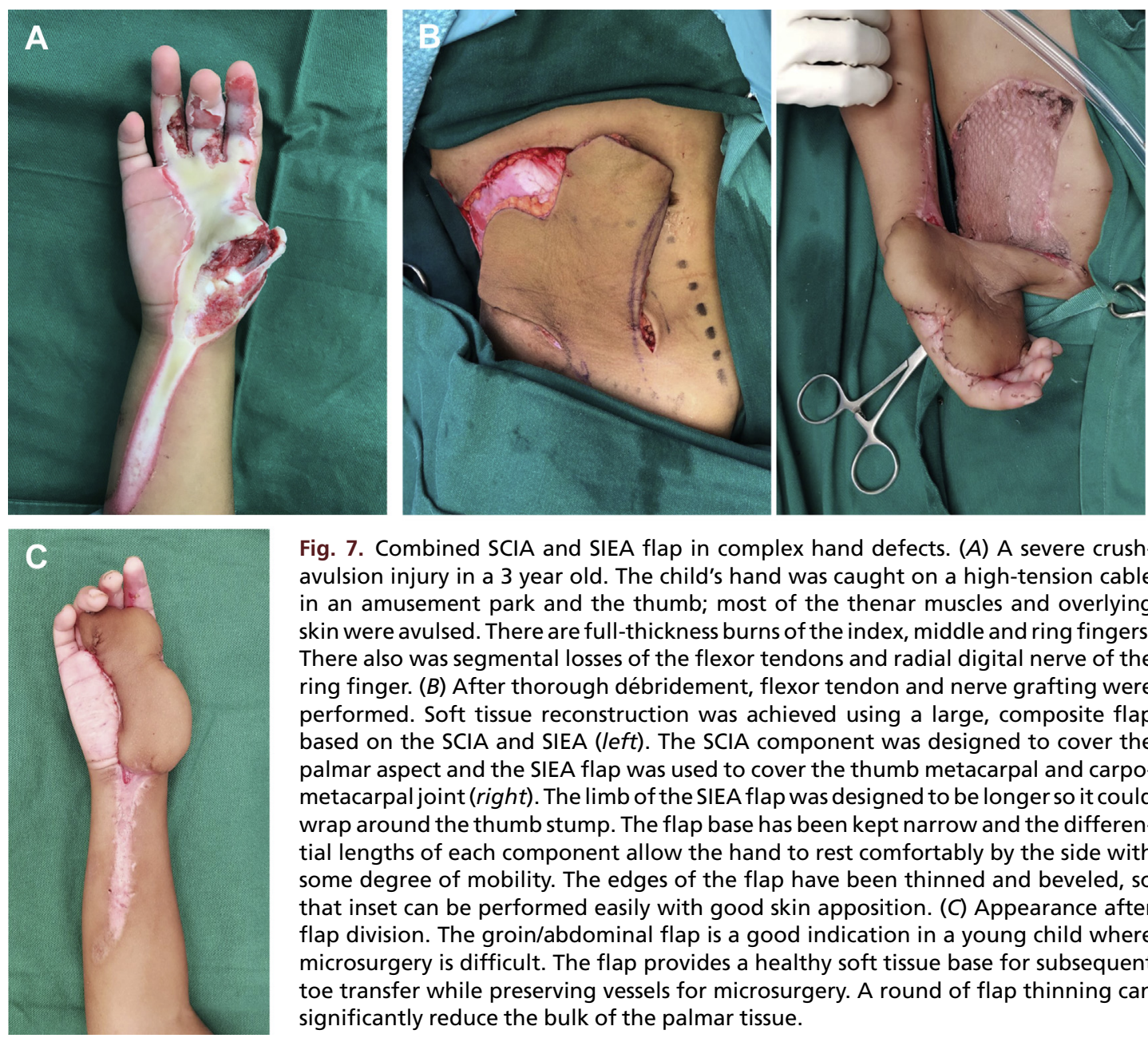

Fig. 7. Combined SCIA and SIEA flap in complex hand defects. $(A)$ A severe crushavulsion injury in a 3 year old. The child's hand was caught on a high-tension cable in an amusement park and the thumb; most of the thenar muscles and overlying skin were avulsed. There are full-thickness burns of the index, middle and ring fingers. There also was segmental losses of the flexor tendons and radial digital nerve of the ring finger. $(B)$ After thorough débridement, flexor tendon and nerve grafting were performed. Soft tissue reconstruction was achieved using a large, composite flap based on the SCIA and SIEA (left). The SCIA component was designed to cover the palmar aspect and the SIEA flap was used to cover the thumb metacarpal and carpometacarpal joint (right). The limb of the SIEA flap was designed to be longer so it could wrap around the thumb stump. The flap base has been kept narrow and the differential lengths of each component allow the hand to rest comfortably by the side with some degree of mobility. The edges of the flap have been thinned and beveled, so that inset can be performed easily with good skin apposition. (C) Appearance after flap division. The groin/abdominal flap is a good indication in a young child where microsurgery is difficult. The flap provides a healthy soft tissue base for subsequent toe transfer while preserving vessels for microsurgery. A round of flap thinning can significantly reduce the bulk of the palmar tissue. 
pedicle because well-vascularized tissue is wasted in the process. Bajantri and colleagues ${ }^{35}$ also described a method of making backcuts to orientate the flap in an appropriate direction to cover dorsal, volar, and radial-sided and ulnar-sided defects. This allowed the hand to rest comfortably and permitted some degree of mobility. The essence of the concept lies in designing a flap with unequal limbsdesigning a $\mathrm{J}$ shape instead of an inverted $U$ shape.

\section{FREE FLAPS}

Free flaps can be broadly divided into fasciocutaneous and muscle flaps, and there are numerous options available. The exact choice of flap depends on size of the defect, type of tissue (glabrous vs nonglabrous skin), whether volume replacement is necessary, the necessary pedicle length, and the need for additional/staged procedures (Fig. 8). These factors must be balanced with the aesthetic principles, discussed previously, and donor site considerations.

\section{Flap Options for Dorsal Skin}

The free flap choices for resurfacing dorsal hand defects include RFF, lateral arm flap, ALT flap, medial sural artery perforator flap, and dorsalis pedis flap. ${ }^{1,36-43}$ These flaps provide good color and texture match. The RFF, dorsalis pedis flap,

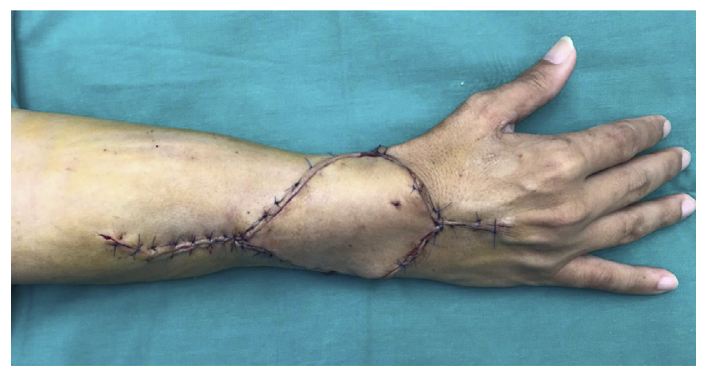

Fig. 8. Free lateral arm flap after resection of synovial sarcoma. This patient presented with a synovial sarcoma arising from the dorsum of the wrist. The tumor had fungated through the skin, and the resection required excision of skin and extensor tendons. Tendon transfers and grafting were performed, and the soft tissue defect was resurfaced using a free lateral arm flap from the opposite upper limb. The thin and pliable fasciocutaneous flap provided an excellent gliding plane for the underlying tendon grafts. The robust, well-vascularized tissue is resilient to subsequent radiotherapy and the relatively long pedicle allows the anastomosis to be performed outside the field of radiotherapy. and medial sural artery perforator flap provide extremely thin and pliable tissue that is ideal for reconstruction of dorsal hand defects. Both the RFF and dorsalis pedis flap are limited, however, by the size of the defect and the corresponding donor defect. Although the foot is a concealed site, skin grafts applied here are more prone to ulceration. The medial sural artery perforator flap is technically challenging and the surgeon should be familiar with the surgical anatomy of this vascular system. ${ }^{44}$ The ALT flap is a versatile flap, and large flaps may be taken with minimal donor site morbidity (Fig. 9). A long pedicle length may be obtained and a flow-through design can be used if revascularization is required. ${ }^{45,46} \mathrm{~A}$ drawback to this flap is that the skin tends to be thick, particularly in women, and staged liposuction and/or debulking may be necessary. ${ }^{47} \mathrm{~A}$ major factor in the choice of these flaps is surgeon preference and technical expertise.

\section{Flap Options for Palmar Skin}

Glabrous skin is a valuable commodity and the plantar aspect of the foot is the only other site besides the hand where such tissue is available. Rodriguez-Vegas ${ }^{48}$ provide an excellent review of the historical descriptions and vascular basis of free glabrous skin flaps from the plantar aspect of the foot. The posterior tibial artery divides into the medial and lateral plantar arteries just after it emerges from the tarsal tunnel, deep to the abductor hallucis muscle. The medial plantar artery (MPA) passes distally within a septum between the abductor hallucis and flexor digitorum brevis muscles and divides further into a lateral (superficial) and medial (deep) branch at the level of the talonavicular joint. Septocutaneous branches from the lateral (superficial) branch of the MPA are the basis of the medial plantar and MPA perforator flaps. Perforators from the medial (deep) branch of the MPA nourish the overlying skin that is the basis of the medialis pedis flap. The medialis pedis flap is thus more dorsal than the medial plantar flap. In their series, the flaps were used for resurfacing small to mediumsized palmar and digital defects. Flaps wider than $2 \mathrm{~cm}$ to $3 \mathrm{~cm}$ required skin grafting, and the majority $(75 \%)$ of skin grafts took partially. This probably is related to the inevitable shear forces and moisture. An additional problem is the short arterial pedicle. These flaps are technically demanding and should be performed in units with strong microsurgical support. 

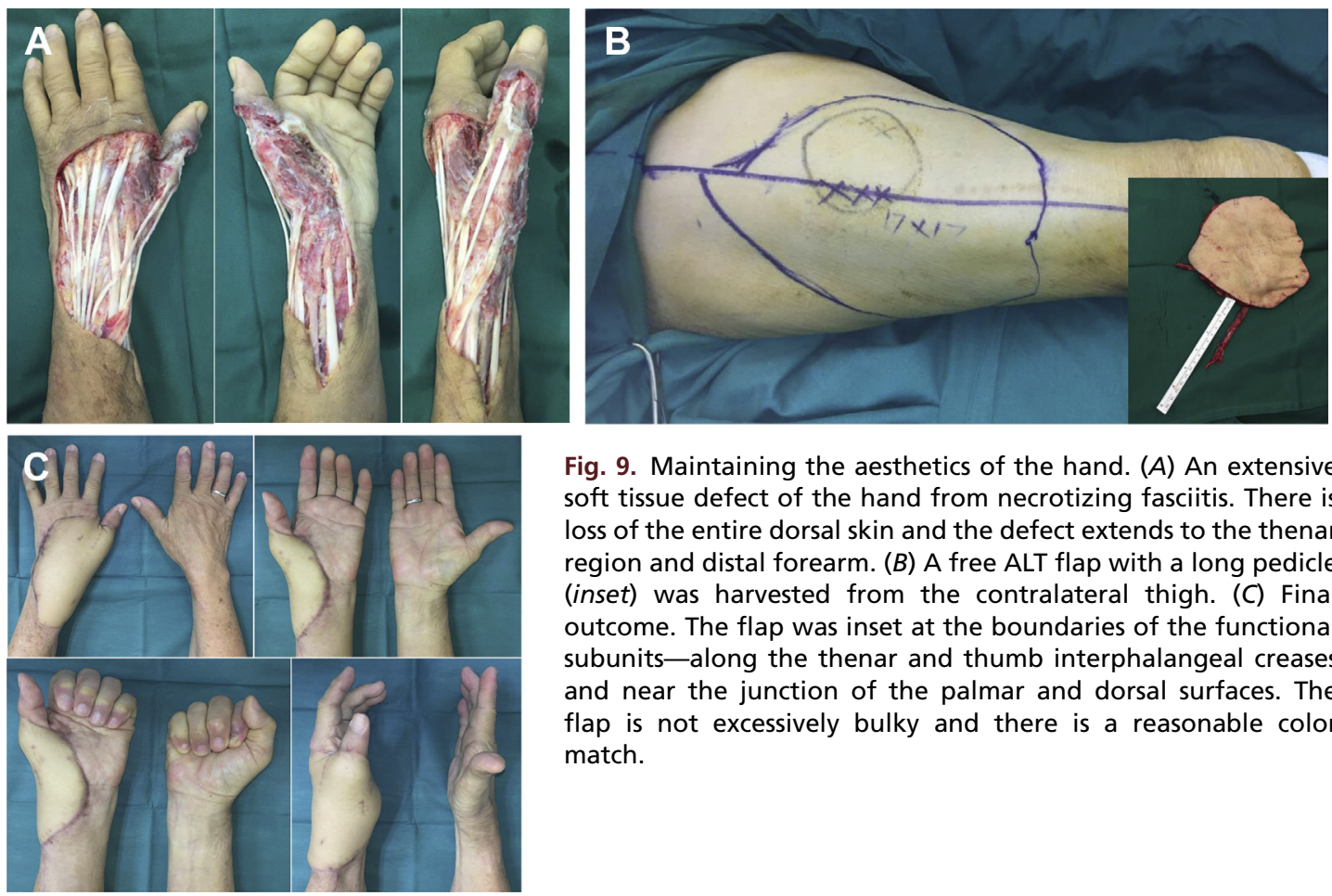

Fig. 9. Maintaining the aesthetics of the hand. (A) An extensive soft tissue defect of the hand from necrotizing fasciitis. There is loss of the entire dorsal skin and the defect extends to the thenar region and distal forearm. (B) A free ALT flap with a long pedicle (inset) was harvested from the contralateral thigh. (C) Final outcome. The flap was inset at the boundaries of the functional subunits-along the thenar and thumb interphalangeal creases and near the junction of the palmar and dorsal surfaces. The flap is not excessively bulky and there is a reasonable color match.

\section{SUMMARY}

There are multiple options available for reconstruction of soft tissue defects of the hand. The main goal of reconstruction is to provide thin, pliable skin that permits mobility. The reconstructive strategy depends on the location and size of the defect, presence of concomitant digital defects, the need for staged procedures, and available resources. Providing an aesthetically pleasing outcome is increasingly becoming a priority, and traditional favorites, such as the RFF, are giving way to perforator-based flaps and selected free flaps. Distant flaps from the groin and lower abdomen continue to be relevant in the microsurgical era. Ultimately, the reconstructive surgeon should have a large armamentarium at his or her disposal so that a strategy can be tailored to patients' specific needs.

\section{REFERENCES}

1. Ono S, Sebastin SJ, Ohi H, et al. Microsurgical flaps in repair and reconstruction of the hand. Hand Clin 2017;33(3):425-41.

2. Guimberteau JC, Delage JP, McGrouther DA, et al. The microvacuolar system: how connective tissue sliding works. J Hand Surg Eur Vol 2010;35(8): 614-22.
3. Ono S, Sebastin SJ, Yazaki N, et al. Clinical applications of perforator-based propeller flaps in upper limb soft tissue reconstruction. J Hand Surg Am 2011;36(5):853-63.

4. Summers BK, Siegle RJ. Facial cutaneous reconstructive surgery: general aesthetic principles. J Am Acad Dermatol 1993;29(5 Pt 1):669-81 [quiz: 682-3].

5. Rehim SA, Kowalski E, Chung KC. Enhancing aesthetic outcomes of soft-tissue coverage of the hand. Plast Reconstr Surg 2015;135(2): $413 e-28 e$.

6. Page R, Chang J. Reconstruction of hand softtissue defects: alternatives to the radial forearm fasciocutaneous flap. J Hand Surg Am 2006;31(5): 847-56.

7. Milner CS, Thirkannad SM. Resurfacing glabrous skin defects in the hand: the thenar base donor site. Tech Hand Up Extrem Surg 2014;18(2): 89-91.

8. Tan RE, Ying CT Jr, Sean LW Jr, et al. Well-camouflaged skin graft donor sites in the hand. Tech Hand Up Extrem Surg 2015;19(4):153-6.

9. Foucher G, Braun JB. A new island flap transfer from the dorsum of the index to the thumb. Plast Reconstr Surg 1979;63(3):344-9.

10. Quaba AA, Davison PM. The distally-based dorsal hand flap. Br J Plast Surg 1990;43(1):28-39. 
11. Timmons MJ. The vascular basis of the radial forearm flap. Plast Reconstr Surg 1986;77(1):80-92.

12. Chang SM, Hou CL, Zhang F, et al. Distally based radial forearm flap with preservation of the radial artery: anatomic, experimental, and clinical studies. Microsurgery 2003;23(4):328-37.

13. Saint-Cyr M, Mujadzic M, Wong C, et al. The radial artery pedicle perforator flap: vascular analysis and clinical implications. Plast Reconstr Surg 2010; 125(5):1469-78.

14. Koshima I, Moriguchi $\mathrm{T}$, Etoh $\mathrm{H}$, et al. The radial artery perforator-based adipofascial flap for dorsal hand coverage. Ann Plast Surg 1995;35(5):474-9.

15. Ho AM, Chang J. Radial artery perforator flap. J Hand Surg Am 2010;35(2):308-11.

16. Becker C, Gilbert A. The ulnar flap. Handchir Mikrochir Plast Chir 1988;20(4):180-3.

17. Georgescu AV, Matei I, Ardelean F, et al. Microsurgical nonmicrovascular flaps in forearm and hand reconstruction. Microsurgery 2007;27(5): 384-94.

18. Mathy JA, Moaveni Z, Tan ST. Perforator anatomy of the ulnar forearm fasciocutaneous flap. J Plast Reconstr Aesthet Surg 2012;65(8):1076-82.

19. Kim KS, Hwang JH. Radial midpalmar island flap. Plast Reconstr Surg 2005;116(5):1332-9.

20. Seyhan T. Reverse thenar perforator flap for volar hand reconstruction. J Plast Reconstr Aesthet Surg 2009;62(10):1309-16.

21. Tapan M, Igde M, Yildirim AR, et al. Reverse thenar perforator flap for large palmar and digital defects. J Hand Surg Am 2018;43(10):956.e1-e6.

22. Orbay JL, Rosen JG, Khouri RK, et al. The glabrous palmar flap: the new free or reversed pedicled palmar fasciocutaneous flap for volar hand reconstruction. Tech Hand Up Extrem Surg 2009;13(3): 145-50.

23. Hao PD, Zhuang YH, Zheng HP, et al. The ulnar palmar perforator flap: anatomical study and clinical application. J Plast Reconstr Aesthet Surg 2014; 67(5):600-6.

24. Soutar DS, Scheker LR, Tanner NS, et al. The radial forearm flap: a versatile method for intra-oral reconstruction. Br J Plast Surg 1983;36(1):1-8.

25. Jin YT, Guan WX, Shi TM, et al. Reversed island forearm fascial flap in hand surgery. Ann Plast Surg 1985;15(4):340-7.

26. Zancolli EA, Angrigiani C. Posterior interosseous island forearm flap. J Hand Surg Br 1988;13(2):130-5.

27. Angrigiani C, Grilli D, Dominikow D, et al. Posterior interosseous reverse forearm flap: experience with 80 consecutive cases. Plast Reconstr Surg 1993; 92(2):285-93.

28. Buchler U, Frey HP. Retrograde posterior interosseous flap. J Hand Surg Am 1991;16(2):283-92.

29. Penteado CV, Masquelet AC, Chevrel JP. The anatomic basis of the fascio-cutaneous flap of the posterior interosseous artery. Surg Radiol Anat 1986;8(4):209-15.

30. Keogh A, Graham DJ, Tan B. Posterior interosseous artery pedicle flap: an anatomical study of the relationship between the posterior interosseous nerve and artery. J Hand Surg Eur Vol 2018;43(10): 1050-3.

31. Zaidenberg EE, Farias-Cisneros E, Pastrana MJ, et al. Extended posterior interosseous artery flap: anatomical and clinical study. J Hand Surg Am 2017;42(3):182-9.

32. Al-Qattan MM, AI-Qattan AM. Defining the indications of pedicled groin and abdominal flaps in hand reconstruction in the current microsurgery era. J Hand Surg Am 2016;41(9):917-27.

33. Chuang DC, Colony LH, Chen HC, et al. Groin flap design and versatility. Plast Reconstr Surg 1989; 84(1):100-7.

34. Sabapathy SR, Bajantri B. Indications, selection, and use of distant pedicled flap for upper limb reconstruction. Hand Clin 2014;30(2): 185-99, vi.

35. Bajantri B, Latheef L, Sabapathy SR. Tips to orient pedicled groin flap for hand defects. Tech Hand Up Extrem Surg 2013;17(2):68-71.

36. Wang HD, Alonso-Escalante JC, Cho BH, et al. Versatility of free cutaneous flaps for upper extremity soft tissue reconstruction. J Hand Microsurg 2017; 9(2):58-66.

37. Meky M, Safoury Y. Composite anterolateral thigh perforator flaps in the management of complex hand injuries. J Hand Surg Eur Vol 2013;38(4): 366-70.

38. Adani R, Tarallo L, Marcoccio I, et al. Hand reconstruction using the thin anterolateral thigh flap. Plast Reconstr Surg 2005;116(2):467-73 [discussion: 474-7].

39. Giessler GA, Schmidt AB, Germann G, et al. The role of fabricated chimeric free flaps in reconstruction of devastating hand and forearm injuries. J Reconstr Microsurg 2011;27(9):567-73.

40. Caroli A, Adani R, Castagnetti C, et al. Dorsalis pedis flap with vascularized extensor tendons for dorsal hand reconstruction. Plast Reconstr Surg 1993; 92(7):1326-30.

41. Lin $\mathrm{CH}$, Lin $\mathrm{CH}$, Lin $Y \mathrm{~T}$, et al. The medial sural artery perforator flap: a versatile donor site for hand reconstruction. J Trauma 2011;70(3):736-43.

42. Xie RG, Gu JH, Gong YP, et al. Medial sural artery perforator flap for repair of the hand. J Hand Surg Eur Vol 2007;32(5):512-7.

43. Jeevaratnam JA, Nikkhah D, Nugent NF, et al. The medial sural artery perforator flap and its application in electrical injury to the hand. J Plast Reconstr Aesthet Surg 2014;67(11):1591-4.

44. Wong $\mathrm{MZ}$, Wong $\mathrm{CH}$, Tan BK, et al. Surgical anatomy of the medial sural artery perforator flap. J Reconstr Microsurg 2012;28(8):555-60. 
45. Zhan Y, Fu G, Zhou X, et al. Emergency repair of upper extremity large soft tissue and vascular injuries with flow-through anterolateral thigh free flaps. Int J Surg 2017;48:53-8.

46. Qing L, Wu P, Liang J, et al. Use of flow-through anterolateral thigh perforator flaps in reconstruction of complex extremity defects. J Reconstr Microsurg 2015;31(8):571-8.
47. Lin TS. One-stage debulking procedure after flap reconstruction for degloving injury of the hand. J Plast Reconstr Aesthet Surg 2016;69(5): 646-51.

48. Rodriguez-Vegas M. Medialis pedis flap in the reconstruction of palmar skin defects of the digits: clarifying the anatomy of the medial plantar artery. Ann Plast Surg 2014;72(5):542-52. 